\title{
Research Paper Recommender System for University Students on the E-Book System
}

\author{
$\operatorname{AUTHOR}(\mathrm{S})$ :
}

Nishioka, Chifumi; Ogata, Hiroaki

\section{CITATION:}

Nishioka, Chifumi ... [et al]. Research Paper Recommender System for University Students on the E-Book System. Proceedings of the 18th ACM/IEEE on Joint Conference on Digital Libraries 2018: 369-370

\section{ISSUE DATE:}

2018

URL:

http://hdl.handle.net/2433/232652

\section{RIGHT:}

(c) ACM 2018. This is the author's version of the work. It is posted here for your personal use. Not for redistribution. The definitive Version of Record was published in 'Proceedings of the 18th ACM/IEEE on Joint Conference on Digital

Libraries', http://dx.doi.org/10.1145/3197026.3203882; この論文は出版社版でありません。引用の際には出版社版をご 確認ご利用ください。; This is not the published version. Please cite only the published version. 


\section{Research Paper Recommender System for University Students on the E-Book System}

\author{
Chifumi Nishioka \\ Kyoto University Library \\ Kyoto, Japan \\ nishioka.chifumi.2c@kyoto-u.ac.jp
}

\begin{abstract}
This paper shows a research paper recommender system for university students. The recommender system is embedded in an e-book system, which displays learning materials (e.g., slides) and is used at lectures. The recommender system suggests papers related to a learning material. The experiment revealed students do not access to recommended papers during the lecture. Instead, they access to research papers when reviewing the lecture and/or working for an assignment.
\end{abstract}

\section{CCS CONCEPTS}

- Information systems $\rightarrow$ Recommender systems; • Humancentered computing $\rightarrow$ E-book readers; • Applied computing $\rightarrow$ Digital libraries and archives;

\section{KEYWORDS}

recommender system, e-book, computer supported learning

\section{ACM Reference Format:}

Chifumi Nishioka and Hiroaki Ogata. 2018. Research Paper Recommender System for University Students on the E-Book System. In $\mathcal{}$ CDL '18: The 18th ACM/IEEE foint Conference on Digital Libraries, fune 3-7, 2018, Fort Worth, TX, USA. ACM, New York, NY, USA, 2 pages. https://doi.org/10.1145/ 3197026.3203882

\section{INTRODUCTION}

So far, a lot of works have developed research paper recommender systems for researchers to assist in finding information. In contrast, this paper proposes a research paper recommender system for university students. The recommender system is embedded into an e-book system BookRoll [2], which displays learning materials (e.g., slides, textbooks) during lectures. It suggests research papers related to a learning material at which a student looks. The motivations of the development are two-fold: (i) Although undergraduate students are interested in research, they have almost no opportunity to know them in lectures. The recommender system provides opportunities to see how what they learn is connected with research. (ii) University libraries operate institutional repositories including research papers. Due to the recent spread of open access policies, the number of research papers in the institutional repositories has increased.

Permission to make digital or hard copies of part or all of this work for personal or classroom use is granted without fee provided that copies are not made or distributed for profit or commercial advantage and that copies bear this notice and the full citation on the first page. Copyrights for third-party components of this work must be honored.

For all other uses, contact the owner/author(s).

fCDL '18, fune 3-7, 2018, Fort Worth, TX, USA

(C) 2018 Copyright held by the owner/author(s)

ACM ISBN 978-1-4503-5178-2/18/06.

https://doi.org/10.1145/3197026.3203882

\author{
Hiroaki Ogata \\ ACCMS, Kyoto University \\ Kyoto, Japan \\ ogata.hiroaki.3e@kyoto-u.ac.jp
}

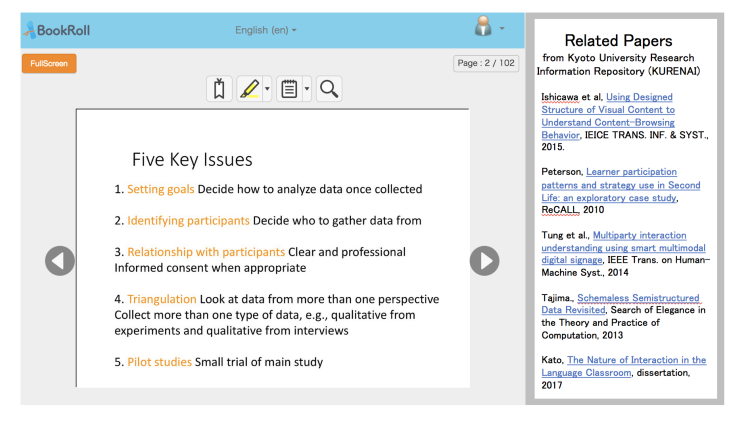

Figure 1: Research paper recommender system on the ebook system BookRoll.

We recommend research papers in the institutional repositories, in order to connect education (i.e., lectures) with research (i .e., research papers) in universities.

\section{RECOMMENDER SYSTEM}

As an initial step, we implement a research paper recommender system for students on an e-book system BookRoll. BookRoll is a web application that displays learning materials. The recommender system suggests research papers related to a learning material at which a student looks. Due to copyright concerns, we cannot mine full texts of research papers. Thus, we mine the research papers using only their titles. As a text mining method, we employ HCFIDF [1], which performs well for mining titles of research papers. Research papers that have highest similarity scores to a learning material are recommended. Figure 1 shows the interface of the recommender system embedded in BookRoll.

\section{EXPERIMENT}

We conduct an experiment to measure how many times and why students access to recommended papers.

Procedure. We deploy the recommender system at a lecture about human interface for third-year undergraduate students on 12/13/2017. The lecture has 44 active students. We observe how many times students have accessed learning materials as well as recommended papers from $12 / 13 / 2017$ to $12 / 20 / 2017$. The lecture gives an assignment to students, which asks students to find three papers about human interface and summarize these papers. The deadline is $12 / 20 / 2017$. After the deadline, we conduct a survey to investigate why they accessed or did not access to recommended papers.

Dataset. The learning material used in the lecture is 86-page slides in Japanese. Regarding candidate items of the recommender system, we use 107, 115 research papers written in Japanese obtained from 


\begin{tabular}{l|l|l}
\hline Question & $n$ & Result \\
\hline Q1. Are you interested in scientific research? (1: not at all - 5: very much) & 44 & $3.36(1.17)$ \\
Q2. Are you interested in contents of the lecture on 12/13/2017? (1: not at all - 5: very much) & 44 & $3.57(0.93)$ \\
Q3. Did you notice that related papers were shown at the right side of BookRoll? (Y/N) & 44 & $56.8 \%$ \\
\hline Q4. If you answer yes for Q3, did you access to recommended papers? (Y/N) & 25 & $48.0 \%$ \\
\hline Q5. If you answer yes for Q4, why did you access? (check at least one reasons) & & \\
Because it seems interesting. & 12 & $25.0 \%$ \\
Because it seems useful for the assignment. & 12 & $75.0 \%$ \\
I clicked without knowing why. & 12 & $16.7 \%$ \\
Q6. If you answer yes for Q4, did you find interesting and/or useful papers? (Y/N) & 12 & $75.0 \%$ \\
\hline Q7. If you answer no for Q4, why did not you access? (check at least one reasons) & & \\
Because it seems unrelated to the contents of the lecture. & 13 & $23.1 \%$ \\
Because I have no interest. & 13 & $23.1 \%$ \\
Because I have no time. & 13 & $38.5 \%$ \\
Another reason & 13 & $15.4 \%$ \\
\hline
\end{tabular}

Table 1: The result of the survey. The first column provides question. In parentheses, answer types are given. The second column shows the number of valid answers. The third column reports the result. If the answer type is the Likert scale, mean and SD are given. If the answer type is $\mathrm{Y} / \mathrm{N}$, the result provides ratio of who answer $\mathrm{Y}$. If the answer type is checkbox, the result reports ratio of who check the reason.

\begin{tabular}{c|rr}
\hline date & learning material & recommended papers \\
\hline $2017-12-13$ & 7298 & 2 \\
$2017-12-14$ & 264 & 3 \\
$2017-12-15$ & 178 & 4 \\
$2017-12-16$ & 237 & 1 \\
$2017-12-17$ & 249 & 0 \\
$2017-12-18$ & 857 & 21 \\
$2017-12-19$ & 3811 & 17 \\
$2017-12-20$ & 1309 & 24 \\
\hline total & 14203 & 72 \\
\hline
\end{tabular}

Table 2: The result of the number of accesses to learning materials and recommended papers.

our institutional repository ${ }^{1}$. As an external knowledge graph for HCF-IDF, we use the JST thesaurus ${ }^{2}$.

\section{RESULT AND DISCUSSION}

Table 2 reports the number of accesses. In terms of the number of accesses to the learning material, please note accesses are counted for each page. Since the learning material has 86 pages and we have 44 active students, each page is accessed at on average 3.75 times. The learning material received most accesses on $12 / 13 / 2017$, the lecture date. Then, the number of accesses drops and increases again towards $12 / 20 / 2017$, the deadline of the assignment. Regarding the number of accesses to recommended papers, we observe few accesses on $12 / 13 / 2017$. The possible reason is that students were focusing on the lecture, thus had no time to see recommended papers. Then, the number of accesses to research papers increases for the deadline of the assignment.

The result of the survey is summarized in Table 1 . It shows students are fairly interested in research and the lecture (Q1 and

\footnotetext{
${ }^{1}$ https://repository.kulib.kyoto-u.ac.jp/dspace/?locale=en

${ }^{2}$ http://www.jst.go.jp/EN/index.html
}

Q2). Only $56.8 \%$ of students noticed that research papers are recommended (Q3). Thus, we need to improve the interface of the recommender system. Among students who noticed recommended papers, $48.0 \%$ of them accessed (Q4). $75.0 \%$ of students with accesses answered recommended papers were interesting or/and useful (Q6). Most reason for the access is to find useful information for the assignment (Q5). The reasons why students did not access are various (Q7). $23.1 \%$ of students without access answered that recommendations included papers unrelated to the learning material. Since research papers in the institutional repository cover many disciplines, it was difficult to retrieve only research papers about human interface in the computer science. For example, the recommender system picks a research paper about human interface in medicine. In the future, we will exploit information such as authors' affiliations (e.g., department) for improving the recommendation strategy. In free comments, we receive positive comments such as the recommender system enables to access research papers easily.

\section{CONCLUSION AND FUTURE WORK}

In this paper, we show a research paper recommender system for students on the e-book system BookRoll, which connects research and education in universities. In the future, we will assess how recommended papers influence on learning activities using logs recorded by BookRoll. Then, we will develop a recommendation strategy that suggests research papers, which stimulates students' learning activities.

Acknowledgments. The research is supported by Grant-in-Aid for Scientific Research (S) No. 16H06304. We appreciate Brendan Flanagan for implementation.

\section{REFERENCES}

[1] C. Nishioka and A. Scherp. 2016. Profiling vs. time vs. content: What does matter for top-k publication recommendation based on Twitter profiles? In $7 C D L$. IEEE, $171-180$.

[2] H. Ogata, C. Yin, M. Oi, F. Okubo, A. Shimada, K. Kojima, and M. Yamada. 2015. E-Book-based learning analytics in university education. In ICCE. 401-406. 